\title{
Brain Oxidative Phosphorylation following Alteration in Head Position in Preterm and Term Neonates
}

\author{
B. LAWSON, E. ANDAY, R. GUILLET, L. C. WAGERLE, B. CHANCE, AND M. DELIVORIA- \\ PAPADOPOULOS \\ Departments of Pediatrics, Physiology, Biochemistry and Biophysics, The University of Pennsylvania School of \\ Medicine, Philadelphia, Pennsylvania 19104
}

\begin{abstract}
An alteration in head position, which effects cerebral blood flow, may increase the risk for intraventricular hemorrhage in the critically ill infant. The purpose of this study was to evaluate in vivo cerebral oxidative metabolism as an index of tissue oxygen delivery reflecting brain blood flow, in healthy preterm and term infants following a change in head position. Cerebral phosphoenergetics using 31 phosphorus nuclear magnetic resonance spectroscopy were measured in 10 preterm and eight term infants following three different head positions: neutral, prone, and supine. All infants were clinically stable at the time of study. The phosphocreatine to inorganic phosphate ratio, an indicator of bioenergetic reserve, was determined. The mean $\pm \mathrm{SD}$ for phosphocreatine to inorganic phosphate ratio in the neutral position in preterm and term infants was $1.08 \pm 0.15$ and $1.12 \pm 0.21$, respectively, and did not change significantly following head turning. These data suggest that any alteration in cerebral blood flow as a result of a change in head position in the healthy neonate may be compensated by physiological and biochemical regulations so that no changes in brain oxidative phosphorylation are measurable. (Pediatr Res 22: 302-305, 1987)
\end{abstract}

\section{Abbreviations}

ICP, intracranial pressure

${ }^{31} \mathrm{P}$ MRS, phosphorus nuclear magnetic resonance spectroscopy

CBF, cerebral blood flow

PCr, phosphocreatine

PD, phosphodiesters

$\mathrm{Pi}$, inorganic phosphate

PME, phosphomonoester

PDE, phosphodiester

The therapeutic management of anoxic brain insult and blunt head trauma in adults and older children takes head position into consideration $(1,2)$. However, optimal head position for critically ill infants at risk for fluctuations in cerebral perfusion and intracranial hemorrhage is controversial. Venographic studies in children indicate that a $90^{\circ}$ head rotation results in obstruction of the ipsilateral internal jugular vein (3). This maneuver impedes outflow from the brain, resulting in increased internal jugular vein pressure and ICP when elastance is high. Anterior

Received February 23, 1987: accepted April 9, 1987

Correspondence Dr. Endla K. Anday, Division of Neonatology, Hospital of the University of Pennsylvania, 2 Maloney Bldg. 36th and Spruce Street. Philadelphia, PA 19104. fontanel tonometry measurements in asphyxiated infants shown a rise in ICP following head rotation $90^{\circ}$ from midline (4). A previous investigation (5), using continuous wave Doppler technique to measure superior sagittal sinus blood velocity in healthy term newborns, showed that turning the head effectively occluded the ipsilateral jugular vein and had profound effects on blood flow velocity.

In order to evaluate the in vivo cellular metabolic response to head position change, the present study used ${ }^{3 !} \mathrm{P}$ MRS, in stable growing preterm and healthy term neonates. Since the relationship of low-to-no CBF to changes in MRS spectroscopy has been documented $(6,7)$, an optimal head position that would minimize changes in cerebral oxidative metabolism was sought.

\section{MATERIALS AND METHODS}

Fundamentals of $M R S$. Atomic nuclei, including ${ }^{1} \mathrm{H},{ }^{13} \mathrm{C}$, and ${ }^{31} \mathrm{P}$, with an odd number of nucleons have an intrinsic magnetism. When an external magnetic field is applied to tissues containing any of these nuclei, the nuclear dipoles align themselves parallel or antiparallel to the field. A second magnetic field can then be applied which, if it is at precisely the right frequency, will cause the alignment of the nuclei to "flip." The nuclei absorb the radiofrequency energy and resonate. The resonant frequency of a given nucleus depends on its chemical environment such that, for example, the ${ }^{31} \mathrm{P}$ nuclei in different phosphorous containing compounds resonate at slightly different frequencies. Therefore, the individual peaks in a magnetic resonance spectrum represent the absorption of radio waves by different compounds, including the three phosphorous atoms in ATP, PCr, $\mathrm{PD}, \mathrm{Pi}$, and PME. The relative amounts of each of these compounds is reflected in the areas under each peak. In turn, the metabolic activity of a tissue can be surmised by calculating the ratios between these metabolites.

In mitochondria, ADP is converted to ATP by drawing on the phosphorous from $\mathrm{PCr}$, another high energy compound. When cells are deprived of an external source of energy, ATP is maintained by the reservoir of $\mathrm{PCr}$. Only when $\mathrm{PCr}$ is exhausted does ATP fall, leaving ADP and $\mathrm{Pi}$. The $\mathrm{PCr} / \mathrm{Pi}$ and $\mathrm{PCr} / \mathrm{ATP}$ ratios are related to the phosphate potential (ATP/ADP $\times \mathrm{Pi}$ and $\mathrm{PCr}$ / $\mathrm{Pi} \times \mathrm{Cr})$ and are thus an index of the energy status of the tissue.

Patients. Details of the in vivo ${ }^{3 !} \mathrm{P}$ MRS technique in neonates were reported previously (8). Eighteen infants were studied in the magnetic resonance spectroscopy laboratory located within the neonatal intensive care nursery of the Hospital of the University of Pennsylvania. All study infants were inborn and were appropriate for gestational age. The term infants, following an uneventful labor and delivery, were studied between days 1 and 3 of life. Preterm infants were studied when stable in room air without evidence of chronic lung disease, ultrasonographic evi- 
dence of intracranial bleed. clinical scizures, or patent ductus arteriosus. No infants received medications at the time of the study.

"P MRS studies were done $1 / \% 101 \mathrm{~h}$ after a feeding. For each study, the infant was placed in a specially designed spectroscopl isolette (Phospho Energetics). A 4-cm radiofrequency surface coil located in a stationary position in the supine aspect of the carriage. was placed on the temporoparietal surface of the head directly above the pinna of the ear. The isolette was then inserted into the bore of a $17.5-\mathrm{cm}$ supereonducting magnet (Phospho) Energetics). Skin temperature, heart rate, respiratory rate. and transcutaneous blood oxygen saluration were continuously monitored. A total of four positions in which the patient was placed were: lying on the right and/or left side with head in neutral position to the body: lying supine with head turned $900^{\circ}$ to the right: lying prone (sleeping position) with head turned to the left Fach study was started by obtaining the left and right neutral position first: prone and supine positions were randomized. Repeat measurement of the left neutral position was performed at the end of the testing to evaluate consistency of the studies and possible relationship of time from last feeding. All studies were performed with the infant lying in a horizontal position.

${ }_{31}$ P MRS examinations were performed at 1.5 Testa ('H frequency 60.1 MHz: "P frequency 24.3 MHz.). Spectra were collected using a Phospho Inergetics MRS spectrometer. Before collection of spectra, fick homogeneity was adjusted with the 'If MRS signal from tissue water for an interval of 5 min for maximal spectral resolution of approximately $0.4 \mathrm{ppm}$. Data were acquired using the following parameters: pulse delay $4 \mathrm{~s}$ : pulse width $50 \mu \mathrm{s}$. sweep width 3000$) \mathrm{H} \%$ A total of 240 tree induction decavs were signal averaged giving a total study time in each position of $16 \mathrm{~min}$. Sampling of phosphorus compounds by the surface coil involves approximately a hemispheric volume with a $2-\mathrm{cm}$ radius (9). Although part of the MRS signal could be derived from scalp muscles, these are very thin in the neonate and therefore contribute minimally to the "P MRS signal. Iourier transformation, curve fitting, and peak measurements were done with the aid of a spectral analysis program (10). Mcasures of areas under the curves for the $\alpha$. $\beta$, and $\gamma$ components of $\triangle \mathrm{TP}, \mathrm{P}(\mathrm{r}, \mathrm{Pi}, \mathrm{PI})$, and PMI: were accumulated and displayed in the form of graphic output as well as final quantitative data. The $\mathrm{PCr} / \mathrm{Pi}$ ratio was used in the analysis as it is related to the phosphate potential and thus a measure of biocnergetic reserve (11).

Table 1. Clinical data in preterm and term infants studied with "I' MR.S

\begin{tabular}{|c|c|c|c|c|c|}
\hline Paticnt & $\begin{array}{l}\text { Birth } \\
w 1 \\
(\mathrm{~g})\end{array}$ & $\begin{array}{l}\text { (iestational } \\
\text { age }(w k)\end{array}$ & $\operatorname{sex}$ & $\begin{array}{l}\text { Age at } \\
\text { study } \\
\text { (days) }\end{array}$ & $\begin{array}{c}\text { Apgar score } \\
(1 \mathrm{~min} / 5 \mathrm{~min})\end{array}$ \\
\hline 1 & $3060)$ & 40 & $\mathrm{I}:$ & 2 & $8 / 4$ \\
\hline 2 & $3760)$ & 40 & $M$ & 3 & $9 / 9$ \\
\hline 3 & 2880 & 4() & I: & 1 & $8 / 9$ \\
\hline 4 & $3260)$ & 40) & $\mathrm{r}:$ & 3 & $8 / 9$ \\
\hline 5 & $2800)$ & 40) & $M$ & 1 and 2 & $9 / 1)$ \\
\hline 6 & 2980 & 40) & I: & 2 & $8 / 9$ \\
\hline 7 & 3.320 & 4() & $M$ & 2 & $7 / 4$ \\
\hline 8 & 2950 & 40 & $\mathrm{M}$ & 1 & $8 / 9$ \\
\hline 9) & 2590 & 36 & $\mathrm{M}$ & 7 & $8 / 9$ \\
\hline 10 & 1660 & 31 & $1:$ & 6 and 14 & $7 / 9$ \\
\hline 11 & 1820 & 34 & I: & 17 and 21 & $9 / 9$ \\
\hline 12 & 2130 & 34 & $\mathrm{I}:$ & 18 & $8 / 8$ \\
\hline 1.3 & 1840 & 32 & $\mathrm{M}$ & 4 & $9 / 9$ \\
\hline 14 & 1280 & 32 & $\mathrm{I}:$ & 18 and 26 & $7 / 8$ \\
\hline 15 & 1946 & 32 & I: & 1 & $8 / 8$ \\
\hline 16 & 1460 & 32 & $\mathrm{M}$ & 1.3 & $8 / 9$ \\
\hline 17 & 1520 & 33 & I: & 6) & $7 / 7$ \\
\hline 18 & 1970 & 35 & M & 14 & $5 / 7$ \\
\hline
\end{tabular}

If an infant became agitated and cried, small amounts of glucose water were given. If an infant was not casy to console. the study was terminated and the intant returned to the nursery. A tepical studi lasted $1{ }^{1}: h$. with a neonatologist present at all times. While potential havards associated with MRS imaging and spectroscopy include bedy exposure to: stattic (I)(') magnetic fields. time-varving magnetic field $(\mathrm{dB} / \mathrm{dT})$ which can induce electrical currents. and absorption of energy from ratho frequency electromagnetic fields which an produce heating. me adverse effects have to date been reported. particularty at the frequency range in which our studies were conducted. The study protocol was reviewed and accepted by the Iniversity of Pennsylvania Committee on Research Involving Human Subjects and signed parental consent was obtained in all cases.

Stutistics. Values are expressed as the mean \pm 1 SD of the mean. Statistical analisis was performed by one-Maty analysis of variance with repeated measurements. Differences between means were determined by paired / lest with Bonferroni correc-

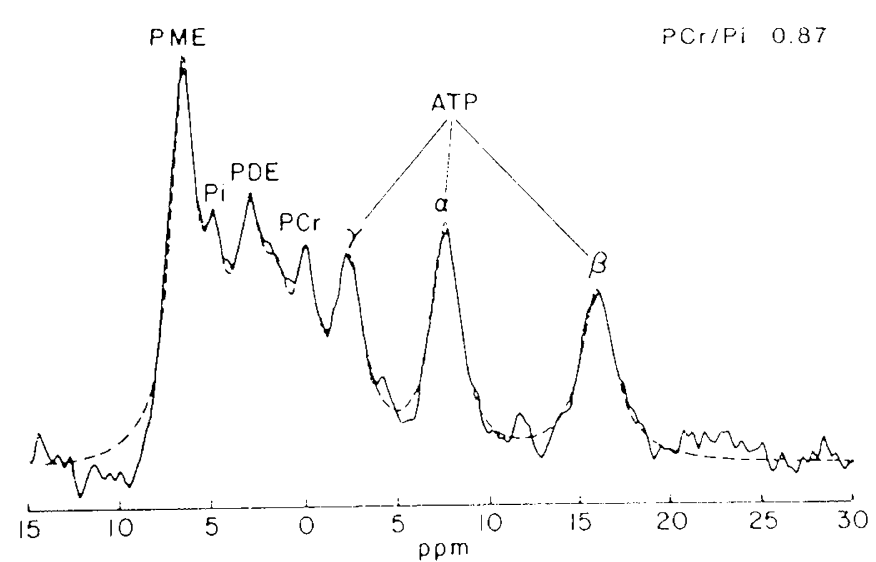

Fig. 1. "P spectrum of brain in a 6 -dat-s)d healthy growing prematture infant of 34 wh postconceptional age using the 1.5 lesla Phospho Energetics spectrometer. Spectral data were obtained for 16 min using al 4-s pulse delar which causes partial saturation of the PME peak. ( hemical

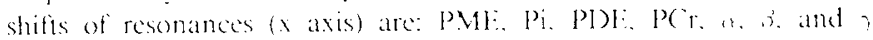
phosphates of ATP. Y axis is signal intensity. The P( $\mathrm{Y} / \mathrm{Pi}$ atio is calculated from signal areas. which are proportional to concemtration.

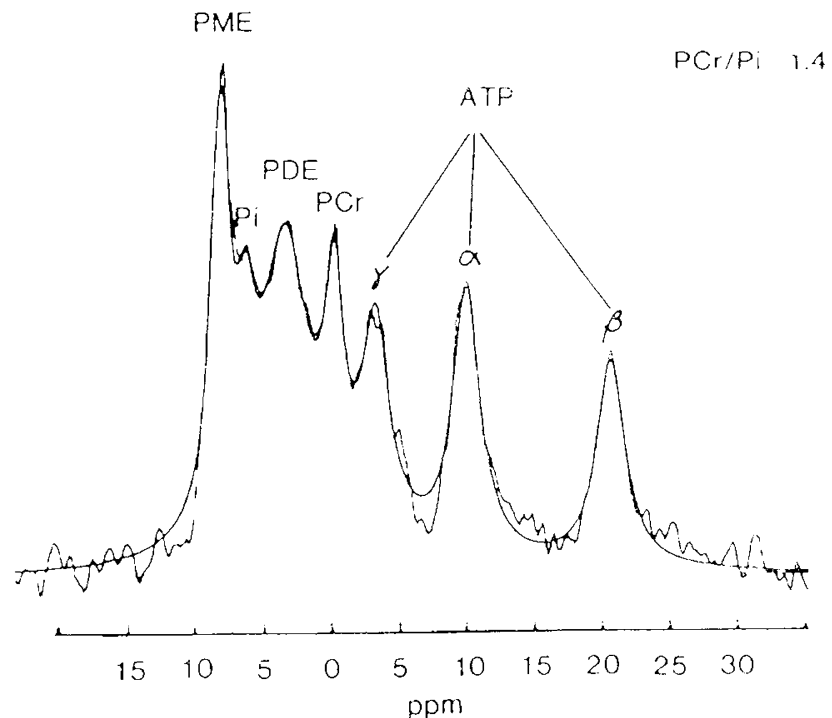

I.ig. 2. ${ }^{3 p}$ spectrum of brain in healthy 1 -day-old intant of to wh postconceptional age. The chemical shilts are as depreted in frgure 1 and $P(\mathrm{r} / \mathrm{Pi}$ ratio is calculated similarly. 
Table 2. $\mathrm{PCr} / \mathrm{Pi}$ ratio in preterm and term infants following alteration of head position (mean $\pm S D$ )

\begin{tabular}{|c|c|c|c|c|}
\hline \multirow[b]{2}{*}{ Group } & \multicolumn{4}{|c|}{ Head position } \\
\hline & Right neutral & Left neutral & Supine & Prone \\
\hline Preterm & $\begin{array}{c}1.08 \pm 0.09 \\
\text { (range } 0.94-1.23 \text { ) }\end{array}$ & $\begin{array}{c}1.11 \pm 0.19 \\
\text { (range } 0.85-1.46)\end{array}$ & $\begin{array}{c}1.08 \pm 0.15 \\
\text { (range } 0.87-1.33 \text { ) }\end{array}$ & $\begin{array}{c}1.05 \pm 0.28 \\
(\text { range } 0.77-1.60)\end{array}$ \\
\hline Term & $\begin{array}{c}1.13 \pm 0.17 \\
\text { (range } 0.93-1.37 \text { ) }\end{array}$ & $\begin{array}{c}1.00 \pm 0.23 \\
\text { (range } 0.71-1.36 \text { ) }\end{array}$ & $\begin{array}{c}1.09 \pm 0.18 \\
\text { (range 0.89-1.47) }\end{array}$ & $\begin{array}{c}1.05 \pm 0.25 \\
\text { (range } 0.79-1.48)\end{array}$ \\
\hline
\end{tabular}

tion when necessary. All differences were considered significant when $p<0.05$.

\section{RESULTS}

A total of 18 infants, 10 preterm and eight term, were studied (Table 1). All infants were healthy and clinically had a normal neurological examination for age. An example of a ${ }^{31} \mathrm{P}$ MRS from a preterm and term infant are shown in Figures 1 and 2, respectively. The seven labeled peaks are evident in both sets of patients. The $\alpha, \beta$, and $\gamma$ components of ATP magnesium complemented ATP probably include contributions from other nuclei triphosphate. The peak labeled PDE is attributable to PD and membrane phospholipids (12). The $\mathrm{PCr} / \mathrm{Pi}$ ratio, an indicator of bioenergetic activity, was calculated in each position.

Control spectra for each infant were considered the spectra obtained with the head in neutral position. After these were obtained from the left and right hemispheres, the baby was placed either prone or supine so that the head was turned $90^{\circ}$. The spectra obtained in these positions also showed the characteristic resonance peaks.

The mean value $\pm \mathrm{SD}$ for $\mathrm{PCr} / \mathrm{Pi}$ in preterm infants was: left neutral $1.11 \pm 0.19$ and right neutral $1.08 \pm 0.09$ (Table 2 ). No significant difference was seen in the $\mathrm{PCr} / \mathrm{Pi}$ values for term infants with the head in the supine and prone positions. The term infants had a mean $\pm \mathrm{SD}$ for $\mathrm{PCr} / \mathrm{Pi}$ ratio of: left neutral $1.00 \pm 0.23$ and right neutral $1.13 \pm 0.17$ (Table 2). Statistical analysis showed no significant change in $\mathrm{PCr} / \mathrm{Pi}$ ratio with head position changes between or within groups (Fig. 3).

\section{DISCUSSION}

Previous studies demonstrated increased intracranial pressure following head position changes in healthy and particularly in birth asphyxiated infants, with the exaggerated response in asphyxiated infants most likely due to a decrease in cerebral autoregulation (13-15). This has led to speculation as to an optimal head position whereby fluctuations in cerebral blood flow could be minimized to decrease the risk of intracranial and or intraventricular hemorrhage in the critically ill neonate. While ${ }^{31} \mathrm{P}$ MRS has been used to assess cerebral metabolism in infants, previous studies were obtained in neonates suffering from hypoxic ischemic episodes, such as asphyxia neonatorum. In the investigation by Hope et al. (16), six normal term and preterm infants were studied for comparison with the asphyxiated newborn subjects. The present study represents one of the largest series of healthy infants measured with ${ }^{31} \mathrm{P}$ MRS and provides insight into the basic characteristic peaks of control ${ }^{31} \mathrm{P}$ spectra. The ${ }^{31} \mathrm{P}$ spectra obtained in our normal term and preterm subjects identifies 7 peaks and are similarly to previous investigations.

Unlike the previous study by Cady et al. (17), we noted a lower $\mathrm{PCr} / \mathrm{Pi}$ ratio in the healthy newborn infant. Part of this difference could be attributed to a saturation factor (18) that was instilled into the computation, because at a 2.25-s pulse interval, full relaxation of the atoms was not allowed but could be corrected for by a factor. In our studies we used a 4-s pulse interval and although we may have been saturating some of the larger peaks, such as PME and $\mathrm{Pi}$, we used a correction factor of 1.05 which
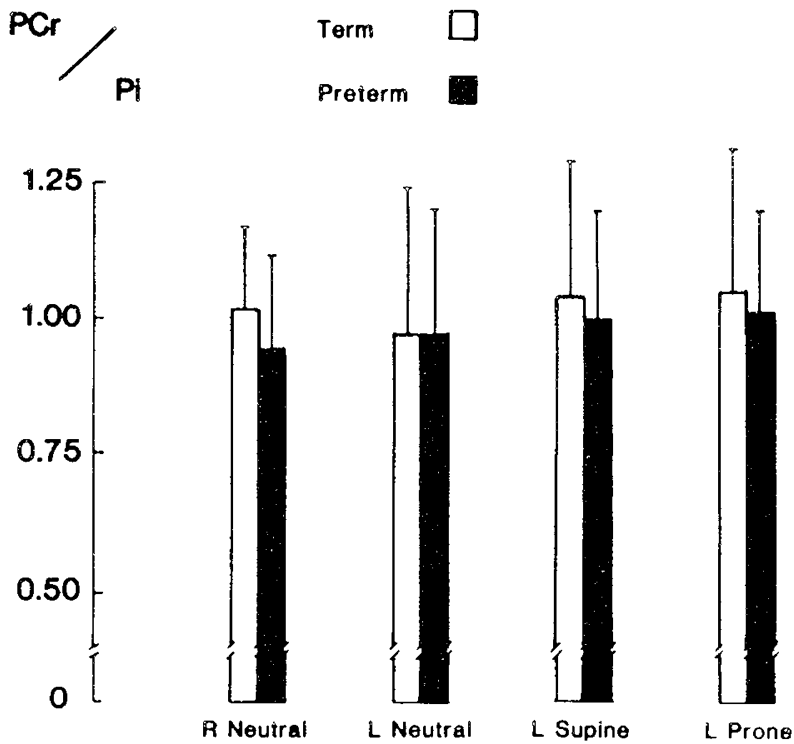

\section{Infant Head Position}

Fig. 3. Effect of varying head position on $\mathrm{PCr} / \mathrm{Pi}$ ratio in healthy preterm and term infants. $\mathrm{PCr} / \mathrm{Pi}$ ratio is the mean value derived from the 10 preterm and eight term infants in each head position. Error bars represents 1 SD. Differences between and within groups are not significant.

was within our significance level and could make the $\mathrm{PCr} / \mathrm{Pi}$ higher. Thus all data can be corrected for saturation.

Further, it is possible to calculate from the range of the data on Table 2 that an average change of \pm 0.25 in $\mathrm{PCr} / \mathrm{Pi}$ ratio could have occurred following alteration of head position. From this we can calculate based on Michaelis-Menten kinetics (19): $\dot{V} /$ $\dot{\mathrm{V}}_{\max }=1 /\left(1+\mathrm{K}_{1} / \mathrm{ADP}+\mathrm{K}_{2} / \mathrm{Pi}+\mathrm{K}_{3} / \mathrm{S}\right)$ where $\dot{\mathrm{V}}=$ rate of oxidative metabolism, $\dot{\mathrm{V}}_{\max }=$ maximum rate of oxidative metabolism, $\mathrm{S}=$ substrate, and $\mathrm{K}=$ rate constant, what the change of tissue $\mathrm{PO}_{2}$ would be, given this difference. If a reasonable assumption about the parsimony of oxygen delivery to the neonate brain can be made, a change of tissue $\mathrm{PO}_{2}$ of a factor slightly greater than 2 could have occurred within the error limits observed. Since $\mathrm{PCr} / \mathrm{Pi}$ is an oxygen indicator itself, we can calculate from the range of our data what would be the possible change of tissue oxygen that could have occurred within our SD as a factor of 2. This calculation emphasizes that while no detectable effects on the $\mathrm{PCr} / \mathrm{Pi}$ ratio were found in the present study, it is possible that small perturbations could have been appreciated if the SE were smaller.

As the process of energy metabolism must take place in an aerobic environment, ${ }^{31} \mathrm{P}$ MRS is a quantitative measure of aerobic metabolism and oxygen delivery to tissues (20). During periods of anaerobic metabolism, as in asphyxia, and in low flow states as intraventricular hemorrhage $(7,16)$, the ability to regenerate ATP and PCr is lowered. Recent studies, in our institutions as well as in others, have shown a correlation of $\mathrm{PCr} / \mathrm{Pi}$ to 
asphyxial episodes $(8,16)$. Other studies have shown "P MRS to be a good indicator of recovery of brain function during experimental asphyxial episodes when correlated to electroencephalography and regional ( $\mathrm{BF}:$ (7).

The findings in the present study are consistent with the Monroe-Kellic hypothesis that the brain, spinal fluid, blood, and other intracranial contents are constant. so that an initial change in volume of one compartment is offset by volume shifts in the other compartments, resulting in minimal change in intracranial pressure (21). Based on previous studies that showed that significant perturbations in ICP and blood flow velocity occurred after a change in head position even in the normal term and healthy preterm infant, these alterations may be compensated by physiological and biochemical regulations so that no change in brain oxidative phosphorylation as measured by "P MRS in a healthy. neonate is detectable.

\section{RIFHRINOCS}

1. Bruce [) A. Berman WA, Schut I 1977 (erebrospinal fluid pressure monitoring

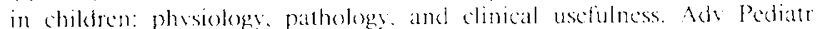
$24: 233-290$

2. Volpe 1.J. Herscovitch P. Pertman IM. Raichle MI 1983 Position cmission tomography in the newhorn: Ixtensive impairment of regional cerebral blood flow with intrawentricular hemorrhage and hemorrhagic intracerebral invellement. Pediatrics 72:589-60)

3. Watson (ill 1974 Jitrect of head rotation on jugular vein blood flow. Arch I ts (')iid $14: 237-234$

4. Fonery JR. Peabody .11. 198.3 Head position atfects intracranial pressure in newborn infants. J Pediatr $1(1,3: 950-953$

5. (owan f. Thoresen M 1985 (hanges in superior sagittal sinus blood welocities due to postural allerations and pressure on the head of the newborn infant. Pediatries $75: 1038-1047$

6. Deley DT ( fordon R1: Hope PI., Parker 1), Reynokds IOOR. Shaw 1). Whitehead $\mathrm{Mi}$ ) 1982. Vonmvasive investigation of cerchral ischemia by phosphorus nuecear magnetic resonance. Pediatries 70$): 310-313$

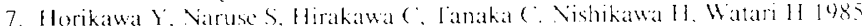
In vivo studies of encergy metaholism in experimental cerchral ischemia using topical magnetic resonance. (hanges in "p) nuckar magnetic resonance spectra compared with clectrocncephalograms and regional cerchral bloud tlow. J (coreb Blood How Matab 5:235-240)

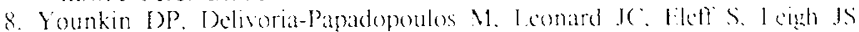
Chance $B$ ig8t Inique aspects of human newborn cerebral metaholism eraluated with phosphorus nuclear magnetic esonance spectroscons. Ann vicurol $16.581-586$

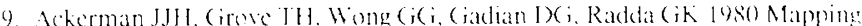
of metabolites in whole animals by "P VNR using surtace coils. Vature $283: 167-170$

10. Hiberman M. Subramanian VH. Haselgrose J (one JB. Vgan IW. (ivulai I (hance $B$ 1984 In vive tame resolved bram phosphorus nuclear magnedic resonance J coreb Blood H low Metah $4: 3.34-3.39$

11. (hanec B 1984t Application of "P NNR to clincal biexhemistr?. An D Acad Sci t2:318...3.32

12. (ivulai 1 . Bolinger 1 . 1984 Phosphorylethanolamine. The mator constutuent of the phosphomonoester peak observed by "P XVR on developing dog hrain

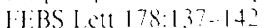

13. I.jpe HP. Mitchell PH 1980 Positoning the pationt with intracranial hypertension: Ifow turning and head rotation affect the inkernal fugular vein. Heart I ung $9: 1031-10,37$

14. Iou HC I assen VA Frib-1 Hansen 8 1979 Impaired autorgutation of cerehal blood flow in the distressed newborn infant. I Pediatr 94:1 $13-121$

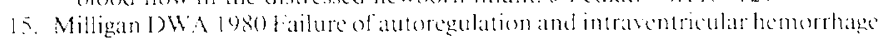
in preterm infants. 1 ancet $1: 896,898$

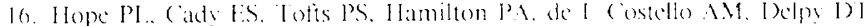

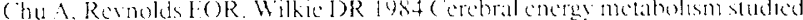
with phosphorus VIIR spectroscops in normal and hirth aspheviated infants. 1.ancet $2: 366 \cdot 3(10)$

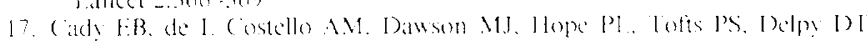
Resnolds EOR. Wilkie DR log: Von-insasio insestigation of cerehral metabolism in newborn infants by phosphorus nuckear magnetic resonance spectrosions. 1ancet 1:1050-1062

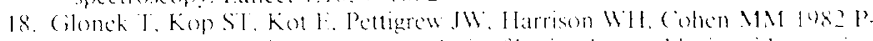
it nuclear magnetic resonance andists of hram: the perchloric acidexcetion spectrum. I Vicurochem 39:1210-1219

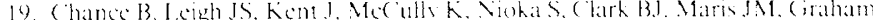
T 1986 Vultiple controk of oxidatise metabolism of living tissues as studiced

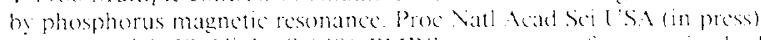

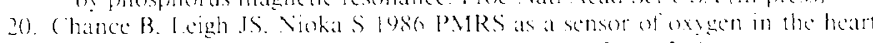

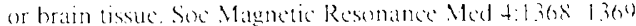

21. I anglitt Th 1969) Increased intracranial pressure. (lin Vouresurg $10: 4,30.45$ 